\title{
Article
}

\section{Mechanisms underlying electro- mechanical dysfunction in the Zucker diabetic fatty rat heart: a model of obesity and type 2 diabetes}

Sultan, Ahmed, Singh, Jaipaul and Howarth, Frank Christopher

Available at http://clok.uclan.ac.uk/30285/

Sultan, Ahmed, Singh, Jaipaul ORCID: 0000-0002-3200-3949 and Howarth, Frank Christopher (2019) Mechanisms underlying electro-mechanical dysfunction in the Zucker diabetic fatty rat heart: a model of obesity and type 2 diabetes. Heart Failure Reviews . ISSN 1382-4147

It is advisable to refer to the publisher's version if you intend to cite from the work. http://dx.doi.org/10.1007/s10741-019-09872-4

For more information about UCLan's research in this area go to http://www.uclan.ac.uk/researchgroups/ and search for <name of research Group>.

For information about Research generally at UCLan please go to http://www.uclan.ac.uk/research/

All outputs in CLoK are protected by Intellectual Property Rights law, including Copyright law. Copyright, IPR and Moral Rights for the works on this site are retained by the individual authors and/or other copyright owners. Terms and conditions for use of this material are defined in the policies page. 
Mechanisms underlying electro-mechanical dysfunction in the Zucker diabetic fatty rat heart: $\mathrm{A}$ a model of obesity and type 2 diabetes

Ahmed Sultan_BSc, MSe, Department of Physiology, College of Medicine \& Health Sciences, UAE University, A1 Ain, UAE.201370241@uaeu.ac.ae, https://orcid.org/0000-0001-5119-0818, -Jaipaul Singh ${ }^{2}$ JSingh3@uclan.ac.uk, http://orcid.org/0000-0002-3200-3949,

Frank Christopher Howarth ${ }^{1 *}$ Tel: 0097137137536, E-mail: chris.howarth@uaeu.ac.ae, http://orcid.org/0000-0002-0224-0556

${ }^{1}$ Department of Physiology, College of Medicine \& Health Sciences

UAE University

P.O. Box 17666, Al Ain, UAE

${ }^{2}$ Jaipatl Singh PhD, DSe, School of Forensic and Applied Sciences,

University of Central Lancashire;

Preston, Lancashire, UK.Email; JSingh3@uclan.ac.uk, http://oreid.org/0000-0002 3200-3949

Frank Christopher Howarth BSe, PhD, Department of Physiology, College of Medicine \& Health Sciences, UAE University, Al Ain, UAE.E-mail: chris.howarth@uaeu.ae.ae, http://oreid.org/0000000202240556

Running title: Mechanical dysfunction in the diabetic heart

\section{Address for correspondence:}

Professor Frank Christopher Howarth, Department of Physiology,

College of Medicine \& Health Sciences, UAE University, P.O. Box 17666, Al Ain, UAE

Tel: 0097137137536

Fax: 0097137671966 


\section{Email: chris.howarth@uaeu.ac.ae}

\section{Abstract}

Diabetes mellitus (DM) is a major and worsening global health problem, currently affecting over 450 million people and reducing their quality of life. Type 2 diabetes mellitus (T2DM) accounts for more than $90 \%$ of DM and the global epidemic of obesity, which largely explains the dramatic increase in the incidence and prevalence of T2DM in the past 20 years. Obesity is a major risk factor for DM which is a major cause of morbidity and mortality in diabetic patients. The electro-mechanical function of the heart is frequently compromised in diabetic patients. The aim of this review is to discuss the pathophysiology of electro-mechanical dysfunction in the diabetic heart and in particular, the Zucker diabetic fatty (ZDF) rat heart, a well-studied model of T2DM and obesity.

\section{Keywords}

\section{Obesity}

Diabetes

Type 2 diabetes mellitus

Heart

Electro-mechanical function of the heart

\section{Introduction}

DM is a major metabolic disorder which is characterized by high blood glucose levels over a prolonged period. DM is a major global health problem. According to statistics from the International Diabetes Federation in 2017 [1], 450 million people worldwide had DM. The number of diabetic patients is expected to reach 629 million by the year 2045. In 2017, there were an estimated 39 million people with diabetes in the Middle East and Northern Africa region. Diabetes is classified into different types. Type 1 diabetes mellitus (T1DM) is characterized by near total pancreatic $\beta$-_cell destruction, usually leading to absolute insulin deficiency. T2DM is the most common form of the disease accounting for more than $90 \%$ of all DM. T2DM is characterized by target cell insulin resistance and a progressive decrease in the 
number of functional insulin-insulin-producing $\beta$-_cells. A third type of DM which affects pregnant women, called Gestational-gestational diabetes, is also characterized by insulin resistance and insulin deficiency. Other forms of diabetes include types related to genetic defects in insulin action, genetic defects of $\beta$-_cell function, and others like endocrinopathies, drug or chemical-induced and diseases of exocrine pancreas [2]. If DM is diagnosed late or left untreated, it can lead to a number of long-term complications including diabetic cardiomyopathy (DCM) and a reduction in the quality of life for the patient. Generally, cardiovascular diseases (CVDs) are the major cause of morbidity and mortality in diabetic patients [3]. In young people with T1DM (8_ $-43 \underline{43}$ years), around 5 out of 1,000 people die from CVDs on a yearly basis, whereas among middle-aged people with T2DM living in high- and middle-middle-income countries, up to 27 out of 1,000 people die from CVDs each year; a third of them die from stroke, and a quarter die from coronary artery disease (CAD) [1]. Electro-mechanical dysfunction of the heart is a frequent occurrence in diabetic patients [4]. Atrial fibrillation (AF) and ventricular arrhythmias (VA) are the most common forms of arrhythmias found in diabetic patients. Left ventricular diastolic dysfunction, increased pulse pressure, and also prolonged QTc of the electrocardiogram are also frequently reported in the diabetic heart. This review discusses the prevalence of obesity and its relationship to DM, normal electro-mechanical activity of the heart, the development of DCM, the ZDF rat as a model of diabetes and obesity, and the mechanisms underlying electro-mechanical dysfunction in the ZDF rat heart.

\section{Obesity: Epidemiology epidemiology and pathophysiology}

Obesity is considered a major health problem globally and it is collectively related to metabolic syndrome. The World Health Organization (WHO) defines obesity as "an abnormal or excessive fat accumulation in adipose tissue, to the extent that health is impaired". The currently accepted classification of obesity for epidemiological purposes defines overweight as a body mass index (BMI) greater than $25 \underline{25} \mathrm{~kg} / \mathrm{m}^{2}$ and obesity starting from a BMI of $30 \underline{30} \mathrm{~kg} / \mathrm{m}^{2}$ [5]. It is an exaggeration of normal adiposity and is a key player in the pathophysiology of DM, insulin resistance, dyslipidemia, hypertension, atherosclerosis, CAD, stroke, liver disease, sleep apnea, osteoarthritis, psychological illnesses, some musculoskeletal conditions, gynecological complications, and cancer, specifically breast and colon [6]. Due to the dramatic increase in prevalence over the last few decades, obesity has become a pressing concern for health care 
officials worldwide. The WHO outlines the severity of the problem in the following global key estimates: in 2014, more than 1.9 billion adults aged $18 \underline{18}$ years and older were overweight. Of these, over 600 million adults were obese. Overall, about $13 \%$ of the world's adult population ( $11 \%$ of men and $15 \%$ of women) were obese in 2014 , while $39 \%$ of adults aged $18-18$ years and over (38\% of men and $40 \%$ of women) were overweight. The worldwide prevalence of obesity has more than tripled between 1975 and 2016, representing 30\% of the world's population. An estimated 41 million children under the age of 5- $\underline{5}$ years were overweight or obese in the year 2014 and this is a major global and Governmentalgovernmental concern [5]. According to the Lancet Commission report, obesity was estimated to affect 2 billion people worldwide in 2015 and the current costs are estimated annually at about 2 trillion US dollars from direct health care costs and lost economic productivity [7].

Obesity is a multi-factorial disorder resulting from a combination of lifestyle, environmental, and genetic factors. Reduction in physical activity, metabolic rate, and thermogenesis eventually decrease energy expenditure leading to increased energy storage and obesity. Some of the causes of obesity include availability of palatable addictive fast food, sedentary lifestyle, leptin resistance, aggressive marketing of food, engineered junk foods, certain medications as well as genetic factors. Figure 1 illustrates some of the factors that contribute to obesity and thus, leading to metabolic syndrome [8]. 


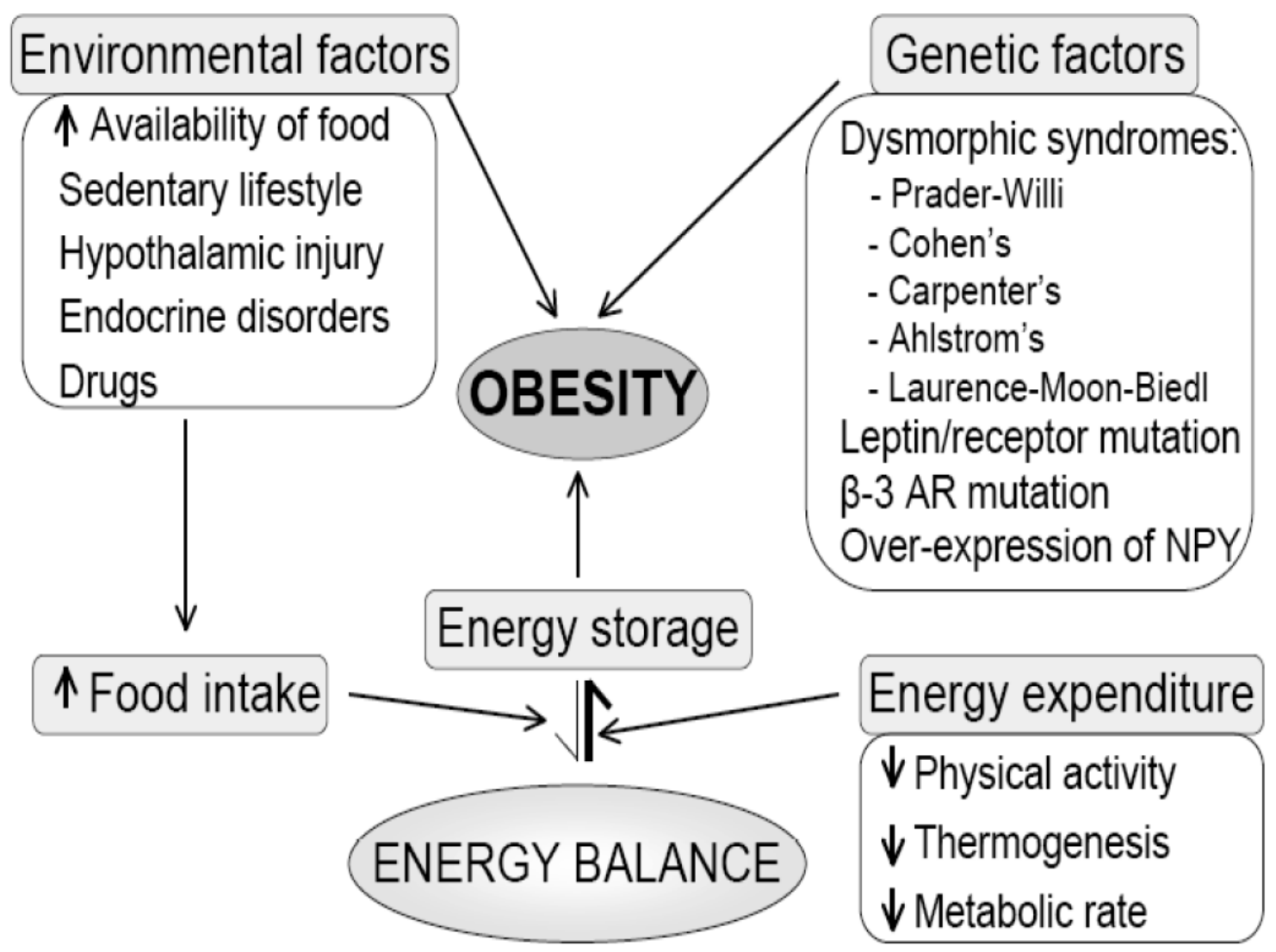

Figure Fig. 1: Flow diagram showing the energy balance and etiology of obesity (Adapted

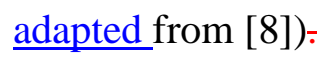

Obesity is characterized by excess fat in the body which contributes to harmful metabolic consequences. Moreover, obesity represents a significant medical and socio-economic burden. According to a recent report, the global cost of treating obesity has risen to 2 trillion US dollars $[7,9]$.

Obesity is a consequence of an adverse increase in adipose tissue mass resulting from increased fat cell size (hypertrophy) or number (hyperplasia) [10, 11]. These two events, together, orchestrate a series of co-morbidities leading to the development of obesity. Targeting adipocyte biology and identifying potential factors that can regulate these processes may be of significant importance in the prevention and treatment of obesity.

\section{Relationship between obesity and type 2 diabetes mellitus}


People who are obese are more likely to develop T2DM. The obesity-induced T2DM is normally referred to as the metabolic syndrome or insulin resistance or adult pre-diabetes leading to persistent high level of blood glucose. In this condition, the body synthesizes and releases enough insulin in the blood, but the cells in the body become resistant to the salutary action of insulin [12].

In recent years, scientists have developed a novel model of T2DM and obesity called the ZDF rat [13]. This model is obese in nature and it develops T2DM as well as inflammation. As such, it is an ideal model to understand how obesity-induced T2DM can lead to DCM. Before discussing

the mechanisms that underlie electro-mechanical dysfunction in the ZDF rat heart, it is important to discuss the metabolic changes that are associated with T2DM.

\section{Type 2 diabetes mellitus and metabolic changes in the body}

In 2017, it was estimated that the number of adults (aged 20_-79-79 years) with DM was around 450 million representing 87_-91\% of all confirmed diabetes worldwide. In addition 212.4 million persons have unreported diabetes or are unaware of their disease [1]. Furthermore, around 1.5 billion people globally have pre-diabetes. Patients with T2DM differ from T1DM because they do not have near total destruction of pancreatic $\beta$-_cells, but instead, suffer from insulin resistance which affects three major tissues of the body: the liver, muscle ${ }_{2}$ and adipose tissues due to the hyperglycemia. In insulin resistance, there is minimal ketosis since insulin diminishes hepatic ketogenesis. The dyslipidemias are similar to those with T1DM and include increased plasma levels of very-_low density lipoproteins (VLDL) and chylomicrons resulting in hypertriacylglycerolemia and lower high density lipoproteins (HDLs) may also be present [14]. Figure 2 shows the metabolic changes which occur in T2DM. 


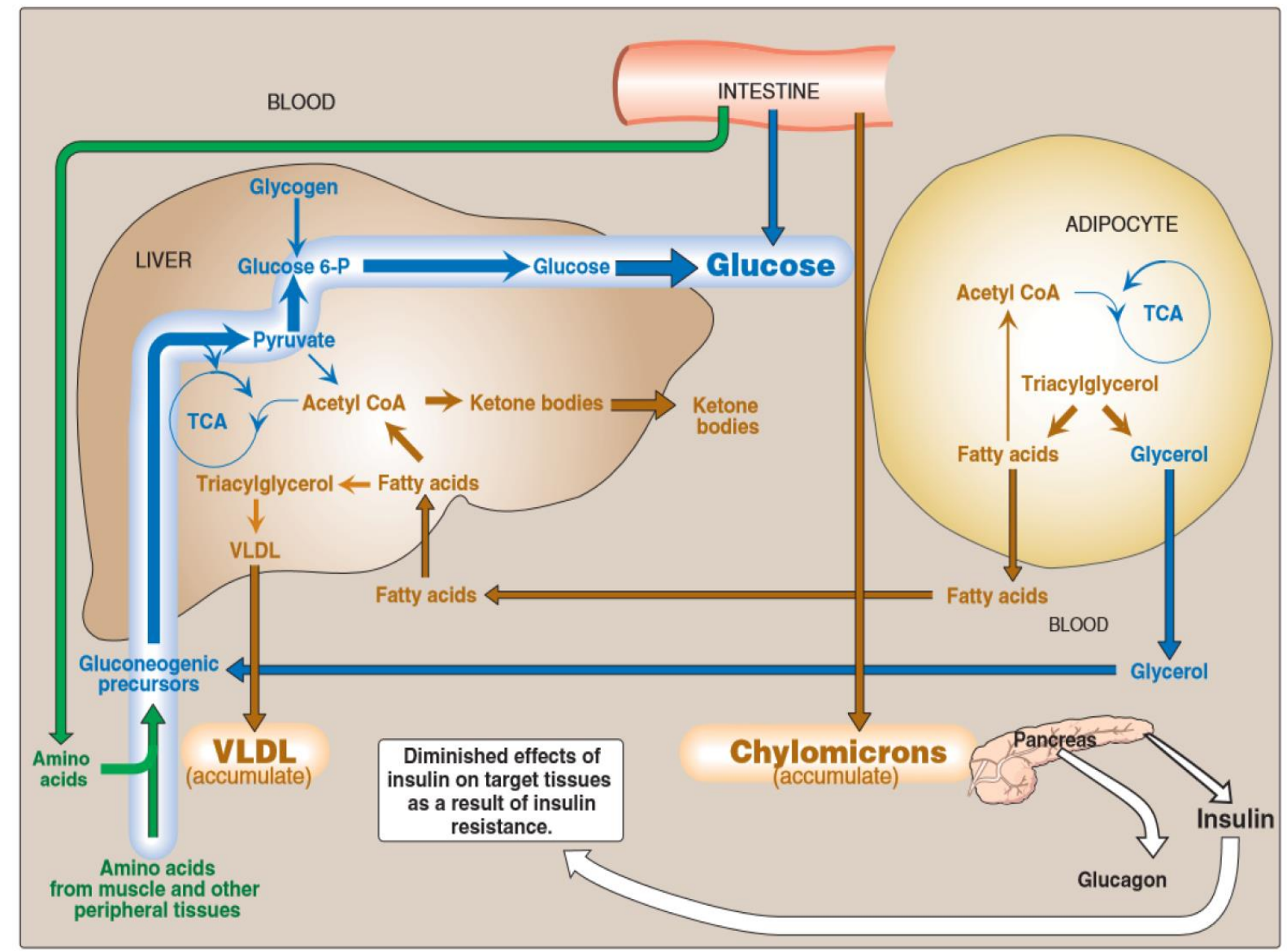

Figure-Fig. 2: Diagram showing metabolic changes occurring in T2DM (Adapted-adapted from [14])-

\section{Electrical activity of the heart}

The heart is a four chambered muscle pump that functions to distribute blood to all the organs in the body [15]. It is eomprised composed of left and right atria and left and right ventricles. The right side of the heart pumps blood through the pulmonary circulation and the left side of the heart pumps blood through the systemic circulation. The contraction of the atria and then the ventricles proceeds in an orderly manner and it is controlled by a specialized electrical conduction system comprising the sinoatrial node (SAN), the atrioventricular node (AVN), left and right bundle branches, and the Purkinje fibers [15]. Electrical activity of the heart is initiated by specialized cells in the SAN which is located in the upper part of the wall of the right atrium. SAN cells have the ability to spontaneously generate action potentials (APs) [16]. 
Action potentials (APs) generated by SAN cells are rapidly conducted across the atria and then, after a brief delay in the AVN, are conducted rapidly across the ventricles. APs in SAN cells, as in other conducting and muscle cells of the heart, are caused by changes of ion conductance in specialized ion channels [15].

\section{Sinoatrial node action potential}

SAN cells are able to generate spontaneous APs and set the normal electrical rate and rhythm in a healthy heart $[17,18]$. SAN cells have unstable resting membrane potentials (Phase-phase 4 ). During Phase phase 4 of the SAN AP, hyperpolarization-activated cyclic-_nucleotide (HCN) channels or "funny current" channels open and there is an inward current carried by $\mathrm{Na}^{+}$and $\mathrm{K}^{+}$. Opening of these channels leads to a small depolarization of the SAN membrane potential. Ltype and T-type $\mathrm{Ca}^{2+}$ currents also contribute to Phase phase 4 of the SAN AP. When the membrane potential reaches threshold, an AP is generated. L-type $\mathrm{Ca}^{2+}$ current is largely responsible for Phase phase 0 . Closure of L-type $\mathrm{Ca}^{2+}$ channels and opening of $\mathrm{K}^{+}$channels, including the delayed rectifier channels $I_{\mathrm{Kr}}$ and $I_{\mathrm{Ks}}$ repolarize the cell giving rise to Phase-phase 3 of the AP $[17,19]$.

\section{Ventricular muscle action potential}

The cardiac muscle AP includes five phases. APs generated in the SAN spreads rapidly across the atria and stimulate atrial muscle contraction. The $\mathrm{P}$ wave of the electrocardiogram represents depolarization of the atria. Electrical activity then travels to the AVN where there is a brief delay before electrical activity spreads rapidly across the ventricular myocardium. The QRS wave of the electrocardiogram reflects ventricular depolarization and the $\mathrm{T}$ wave reflects ventricular repolarization $[17,18]$.

Phase 0 of the AP is caused by the opening of fast voltage-gated $\mathrm{Na}^{+}$channels, and rapid regenerative influx of $\mathrm{Na}^{+}$, which depolarizes the membrane from the resting membrane potential ( $-90 \underline{90} \mathrm{mV}$ ) to around $+30 \underline{30} \mathrm{mV}$. The $\mathrm{Na}^{+}$channels quickly inactivate and a transient opening of $\mathrm{K}^{+}$channels produces a transient early repolarization and Phase phase 1 of the AP. The plateau Phase-phase 2 mainly results from opening of voltage-gated L-type $\mathrm{Ca}^{2+}$ channels. The closure of L-type $\mathrm{Ca}^{2+}$ channels and opening of voltage-gated $\mathrm{K}^{+}$channels lead to 
repolarization and Phase phase 3 of the AP. Finally, the membrane potential returns to resting levels $[20,21]$.

The AVN may be thought of as the secondary pacemaker of the heart. The AVN is a subendocardial structure located in the inferior-posterior right atrium, within an anatomic region bordered posteriorly by the coronary sinus ostium, superiorly by the tendon of Todaro and anteriorly by the septal tricuspid valve annulus. This anatomic region is also commonly referred to as "triangle of Koch".". The AVN beats at a lower rate than the SAN, around 40--60 beats per minute. The delay in signal transmission in the $\mathrm{AVN}$ is to allow the atria to finish contraction before the ventricular chambers contract. After passage through the AVN, the wave of depolarization spreads rapidly to the Bundle of His, left and right bundle branches of the Purkinje system ${ }_{2}$ and across the ventricular myocardium (QRS wave) $[17,19,21]$.

\section{Excitation-contraction coupling}

The process of excitation-contraction coupling (ECC) connects the electrical with mechanical activity of heart muscle (Figure-Fig. 3). The generation of an electrical AP leads to opening of Ltype $\mathrm{Ca}^{2+}$ channels during Phase phase 2 of the AP followed by a small influx of $\mathrm{Ca}^{2+}$. This small influx of $\mathrm{Ca}^{2+}$ binds to ryanodine receptors (RYR) in the sarcoplasmic reticulum (SR) and triggers a large release of $\mathrm{Ca}^{2+}$ from the $\mathrm{SR}$. This process is referred to as $\mathrm{Ca}^{2+}$-induced $\mathrm{Ca}^{2+}$ release $(\mathrm{CICR})$ and leads to a rise in cytoplasmic $\mathrm{Ca}^{2+}$ concentration, normally referred to as the $\mathrm{Ca}^{2+}$ transient. The elevated cytosolic $\mathrm{Ca}^{2+}$ binds to Troponin- $\mathrm{C}(\mathrm{TnC})$ which causes

Tropomyosin $(\mathrm{Tm})$ to reveal the active binding site of the myosin myofilaments causing a shift and binding of myosin to actin proteins causing muscle contraction. After completing the cycle, the muscle relaxes and the $\mathrm{Ca}^{2+}$ is released from the myofilaments. $\mathrm{Ca}^{2+}$ that was released from the $\mathrm{SR}$ is returned to the SR via the $\mathrm{Ca}^{2+}$-ATPase (SERCA) pump. $\mathrm{Ca}^{2+}$ that entered the cell via L-type $\mathrm{Ca}^{2+}$ channels is extruded from the cell primarily via the $\mathrm{Na}^{+} / \mathrm{Ca}^{2+}$ exchanger (NCX), but to a lesser extent via the cell membrane $\mathrm{Ca}^{2+}$ ATPase (Figure-Fig. 3) [18, 19, 22-26]. 


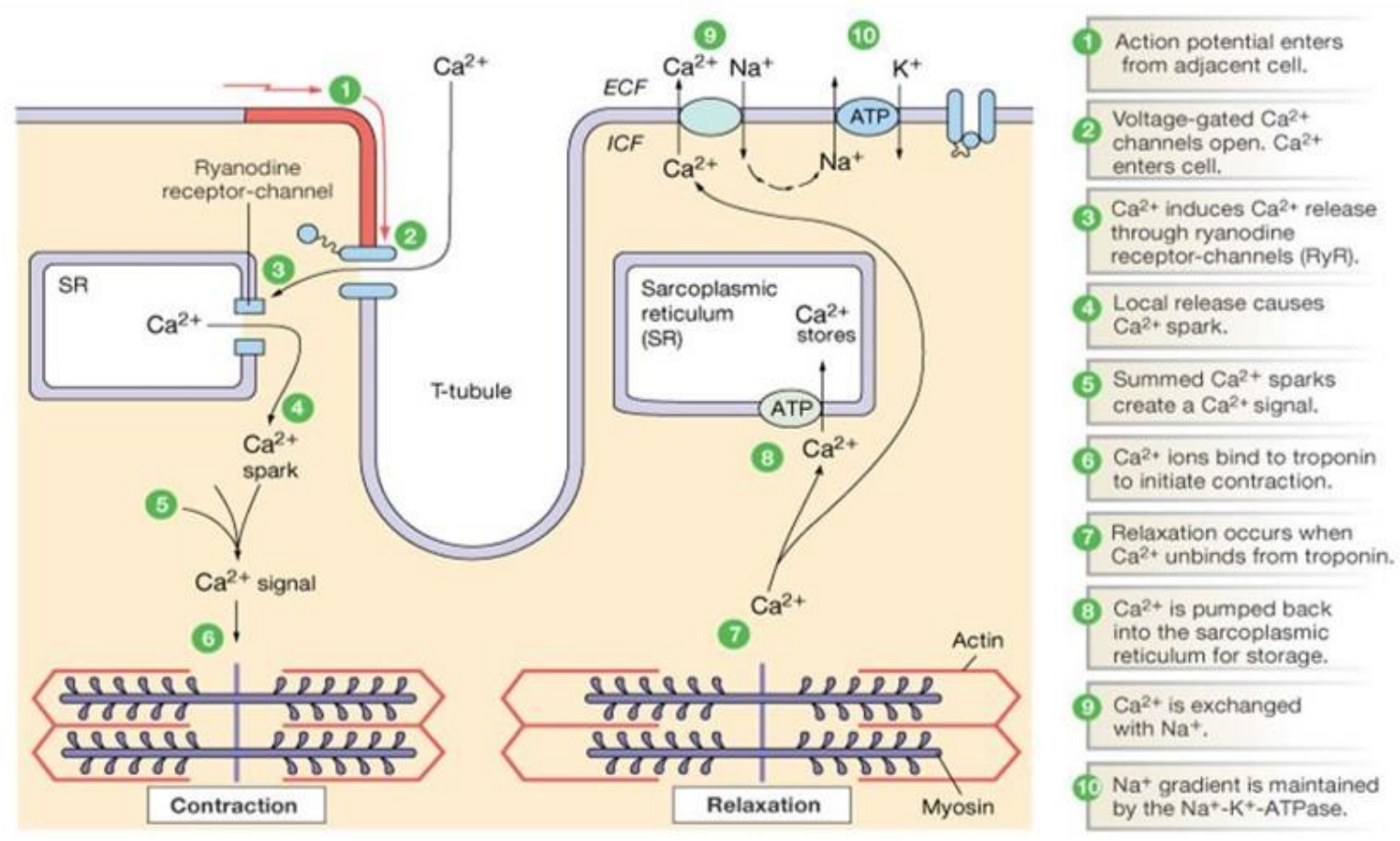

Figure-Fig. 3: Diagram showing the process of excitation-contraction coupling in the heart (Adapted-adapted from [23]).

\section{Voltage-gated ion channels of the heart}

Since the propagation of APs depends on voltage-gated ion channels, it is helpful to discuss these

channels in more detail, as their dysfunction can results in CVDs. Voltage-gated ion channels are transmembrane proteins that control physiological processes such as cardiac muscle cell contraction and relaxation (Figure-Fig. 4). Voltage-gated $\mathrm{Na}^{+}$channels and voltage-gated $\mathrm{Ca}^{2+}$ channels are present in the cell membranes of most excitable cells [20, 21, 27, 28].

Voltage-gated $\mathrm{Na}^{+}$channels are composed of one $\alpha$ subunit and one or two $\beta$ subunits. The $\alpha$ subunit consists of four homologous domain regions (I-IV) of six transmembrane spanning segments ( $\mathrm{S} 1$ - $\mathrm{S} 6$ ) and a pore-pore-forming loop. It is hypothesized that the $\mathrm{S} 4$ segment is the voltage sensor and channel gating modulator. The pore region, which allows the passage of $\mathrm{Na}^{+}$ ions, also has a fatty acyl chain that allows the passage of hydrophobic small blocking drugs. The pore-region of the $\mathrm{Na}^{+}$channel $\alpha$ submit, an "Asp-Glu-Lys-Ala" (DEKA) motif, determines $\mathrm{Na}^{+}$ selectivity [20, 21, 27, 28]. 
Voltage-gated $\mathrm{Ca}^{2+}$ channels are proteins that allow the passage of $\mathrm{Ca}^{2+}$ into cells. They are hetero-oligomeric complexes of different subunits of $\alpha, \beta, \gamma_{2}$ and $\delta$ that assemble into 5 units, the pore-forming $\alpha$ subunit ( $\alpha 1)$ and at least two accessory subunits $\alpha 2 \delta$ and $\beta \beta_{-;}$hence, the term "hetero-oligomeric". So far ${ }_{2} 10$ cloned $\alpha$-subunits have been identified and they make up five different families including $\div$ (1) L-type $\mathrm{Ca}^{2+}$ dihydropyridine-sensitive (high voltage long or slow activating), (2) T-type $\mathrm{Ca}^{2+}$ (low voltage or transient), (3) $\mathrm{N}$-type $\mathrm{Ca}^{2+}$ (neuron pre-synapse), (4) P-type $\mathrm{Ca}^{2+}$ (Purkinje cells) and (5) R-type $\mathrm{Ca}^{2+}$ (resistant to peptide toxins). The T-type and Ltype $\mathrm{Ca}^{2+}$ channels variously contribute to pacemaker cell APs. Each $\alpha$-subunit is composed of four homologous regions (I_-IV) of six transmembrane domains (S1_S6) where the S4 is also responsible for the gating function. The $\alpha 2 \delta$ and $\beta$ subunits enhance expression and modulate the voltage dependence and gating kinetics of the $\alpha 1$ subunit [20, 23, 24].

Potassium $\left(\mathrm{K}^{+}\right)$channels can be classified into three main groups depending on their poreforming channel structures. The first group of voltage-dependent $\mathrm{K}^{+}$currents $\left(\mathrm{K}_{\mathrm{v}}\right)$ derived from six families of channel proteins are based upon Drosophila melanogaster nomenclature. $\mathrm{K}^{+}$ currents included in this group consist of the transient outward $\mathrm{K}^{+}$channels, $\mathrm{Ca}^{2+}$ activated $\mathrm{K}^{+}$ channels, and KCNQ channels, all of which form tetrameric structures eomprised composed of six transmembrane segments (S1_S6) subunits and cytoplasmic N- and C-termini. The S1_S4 segments move in response to voltage changes, functioning as the voltage sensor for the channel. The second group of $\mathrm{K}^{+}$channels consists of two transmembrane segments (S1-S2), conducting three inward $\mathrm{K}^{+}$currents: the inward-rectifying $\mathrm{K}^{+}\left(\mathrm{K}_{\mathrm{ir}}\right)$ channels, ATP-sensitive $\mathrm{K}^{+}$(KATP) channels, and $\mathrm{G}$ protein-coupled inwardly-rectifying $\mathrm{K}^{+}$(GIRK) channels [29]. The S1 and S2 segments are connected by a pore-forming P-loop. The third group of $\mathrm{K}^{+}$channels is the most abundant, with more than 50 members all of which have a two-pore (P1 and P2) structure with four transmembrane segments (S1-S4). The glycine-tyrosine-glycine (GYG) motif in the pore region is the critical sequence responsible for $\mathrm{K}^{+}$selectivity. A gene called "KCNH2" encodes the Kv11.1 channel, also known as the human Ether-à-go-go related gene (hERG), which carries the inward delayed rectifier $\mathrm{K}^{+}$current $\left(\mathrm{I}_{\mathrm{Kr}}\right)$, a key component of repolarization during the cardiac AP. Blockade of $\mathrm{I}_{\mathrm{Kr}}$ delays cardiac repolarization, thereby prolonging AP duration (APD) and the QT interval of the electrocardiogram, and potentially increases the risk for the development of the cardiac arrhythmia such as: Torsades de Pointes (TdP). The molecular structures of the different cation channels are shown in Figure-Fig. 4 [23, 25, 26, 30]. 
A. Voltage-gated $\mathrm{Na}^{+}$channels

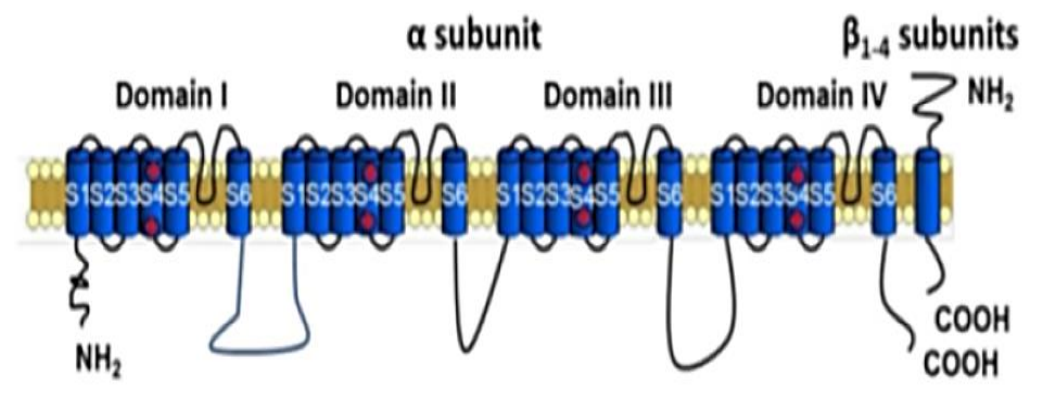

B. Voltage-gated $\mathrm{Ca}^{2+}$ channels

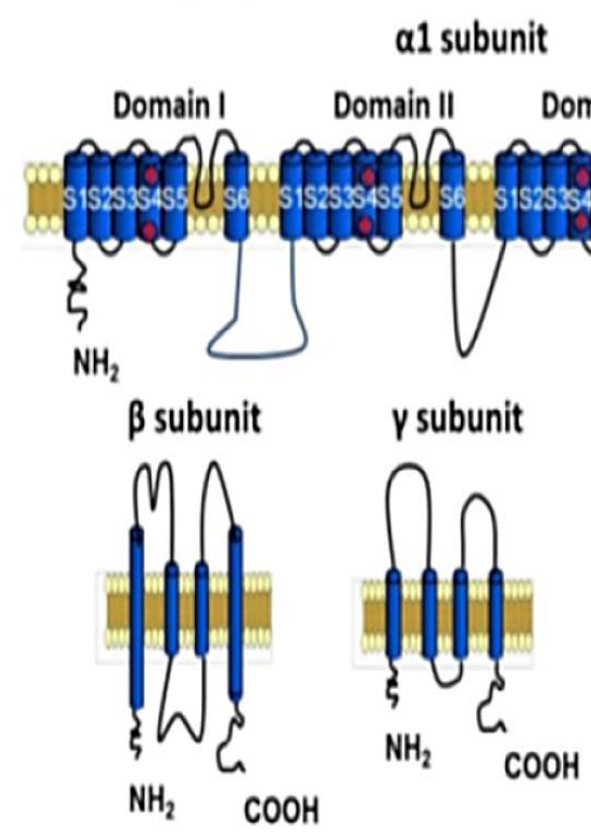

C. $\mathrm{K}^{+}$channel a subunits

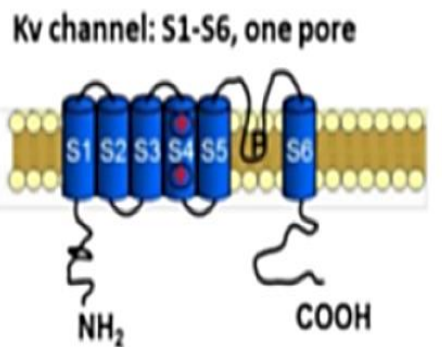

Kir channel: S1-S2, one pore

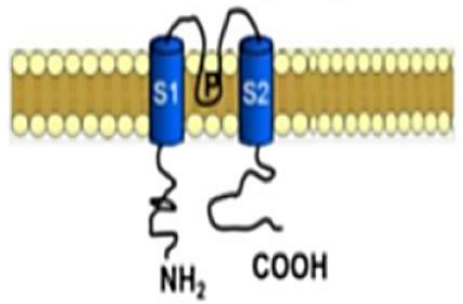

K2P channel: S1-S4, two pore

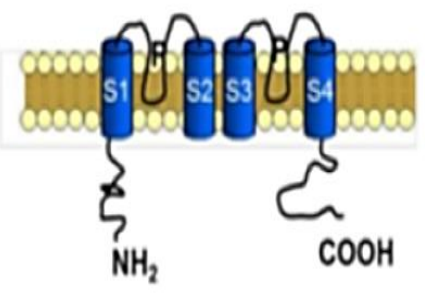

Figure-Fig. 4: Diagram showing the structure of voltage-gated $\mathrm{Na}^{+}, \mathrm{Ca}^{2+}{ }_{2}$ and $\mathrm{K}^{+}$channels (Adapted-adapted from [31]):

\section{Development of diabetic cardiomyopathy}

Since more than $80 \%$ of obese patients usually die from DCM, then it is important to understand the pathophysiology of this disease and the associated risk factors which include dyslipidemia, hypertension, diet, obesity, smoking, reduced physical exercise, and genetics [32, 33]. It is well known that DM can induce both short-term as well as long-term complications due to damage of the blood vessels in different organs of the body. Some of these complications include macrovascular diseases such as hypertension, hyperlipidemia, heart attacks, coronary artery 
disease, strokes, cerebral vascular disease, and peripheral vascular disease. Other complications include microvascular diseases such as retinopathy, nephropathy, and neuropathy. Macrovascular complications, and to a lesser extent microvascular as in nephropathy, can lead to DCM [34-36]. DCM is a major adverse complication of T2DM which is characterized by defects in both diastolic and systolic function. In T2DM, factors contributing to DCM include defective regulation of cellular $\mathrm{Ca}^{2+}$ homeostasis due to dysregulation of cellular $\mathrm{Ca}^{2+}$ transporting proteins. First, there is a significant impairment in sarcolemmal $\mathrm{Na}^{+} / \mathrm{Ca}^{2+}$ exchanger activity, which limits the ability of the diabetic heart to extrude $\mathrm{Ca}^{2+}$ leading to an elevation in diastolic $\left[\mathrm{Ca}^{2+}\right]_{\mathrm{i}}$. Second, there is a decrease in $\mathrm{Na}^{+} / \mathrm{K}^{+}$ATPase activity, which is known to increase $\left[\mathrm{Ca}^{2+}\right]_{\mathrm{i}}$ secondary to a rise in $\left[\mathrm{Na}^{+}\right]_{\mathrm{i}}$. Third, $\mathrm{Ca}^{2+}$ influx via the $\mathrm{Ca}^{2+}$ channel may be increased [32]. Fourth, the activity of SERCA is reduced and fifth, the RYR functions in an asynchronous manner which may also lead to elevated diastolic $\mathrm{Ca}^{2+}[29,31]$. In addition, dysfunction of both vascular endothelial cells and cardiomyocytes can also contribute to the pathogenesis of DCM due hyperglycemia leading to oxidative stress, elevation in methylglyoxal, fibrosis, hypertrophy, and remodeling of the heart [33,37]. Since DCM is a major hallmark of DM including both T1DM and T2DM and since obesity also plays a role in the development of T2DM, it is relevant to discuss the mechanism(s) of obesity-induced DM, as in the ZDF rat.

\section{Zucker diabetic fatty rat as an experimental model of type 2 diabetes mellitus and obesity}

Strain identification

ZDF rats were derived from the Zucker fatty (ZF) rat and is are widely used for T2DM research. The ZF rat inherits obesity as an autosomal Mendelian recessive trait. The ZF rat has a missense mutation (fatty, fa) in the leptin receptor gene (Lepr) which develops obesity without DM. A missense mutation (an A to $\mathrm{C}$ conversion at nucleotide position 806) was found in the extracellular domain of all the isoforms in ZF (fa/fa) rats, which resulted in an amino acid change from glycine (Gln) to proline (Pro) at +269 . These $\mathrm{Ob}-\mathrm{R}$ isoform messenger ribonucleic acids (mRNAs) were present in the brain from ZF (fa/fa) rats at similar amounts to those in their

lean littermates [38]. These rats are obese, hyper-insulinemic, and hyperphagic,-; however, blood glucose remains at normal levels. ZF rats usually eat more than normal rats, so their response to the alterations in food and cold is more like that of normal rats than rats with hypothalamic 
obesity. The hypertriglyceridemia which characterizes these animals is normally due to the increased hepatic production of VLDL. Adipocytes are increased both in number and in size ${ }_{2}$ and usually $_{2}$ the subcutaneous fat depot has the highest number of fat cells. Lipogenesis from glucose is rapid in young animals but declines with age. Enzymatic patterns of glycolysis and gluconeogenesis appear to reflect the altered internal environment rather than specific defects. Endocrine changes in the fatty rat include reduced levels of glucagon, hyper-insulinemia, hypothyroidism, then during their first introduction they had an impaired reproductive function [39].

From a ZF rat colony [13]' a new strain fa/fa homozygous male rats with reproductive ability were found by mating fa/fa males and fa/+ heterozygous females. This new strain of fa/fa male rats exhibited DM-selective breeding and relatively high blood glucose levels at $10 \underline{10}$ weeks of age resulted in the establishment of a diabetic strain that were designated: ZDF -Lepr $f a$. These homozygous fa/fa male rats developed DM as early as $10 \underline{10}$ weeks of age, reaching $100 \%$ incidence by $21 \underline{21}$ weeks of age, while none of the fa/+ male rats developed DM. The phenotypic characteristics of this diabetic strain are distinct from those of normo-glycemic ZF rats. The ZDF rat strain with a high reproductive efficiency serves as a useful animal model of T2DM [13].

Various studies have demonstrated progressive functional and structural changes in both the heart and kidney, starting as early as $16 \underline{16}$ weeks, without evidence that one pathology precedes or causes the other in the ZDF rat [40].

\section{Metabolic changes in the Zucker diabetic fatty rat heart}

Several studies have reported that marked metabolic changes in the ZDF rat heart compared to healthy controls were elevated $[40,41]$. There is an increase in ROS production and lipid peroxidation, an increase in cytochrome (CYP4502E1) activity accompanied by increased protein expression, oxidative protein carbonylation, and increased expression of other oxidative stress marker proteins including HO-1 and iNO. Similarly, glutathione (GSH) concentration and activities of GSH-dependent enzymes, glutathione S-transferase, and GSH reductase are also significantly increased in ZDF rat heart tissues suggesting a compensatory defense mechanism [41]. The activities of mitochondrial respiratory enzymes complex I and complex IV are reduced 
in the ventricle of ZDF compared to Zucker lean (ZL) control rats. Other studies have reported decreased expression of IкB- $\alpha$ and phosphorylated-JNK in diabetic heart tissue. It was also reported that mitochondrial dysfunction and increased oxidative stress in ZDF rats might be associated, at least in part, with altered NF- $\mathrm{B} / \mathrm{JNK}$ JNK-dependent redox cell signaling [41].

In another study, contractility of ventricular myocytes was well maintained regardless of altered mechanisms of $\mathrm{Ca}^{2+}$ transport and a changing pattern of mRNA in aged ZDF rat heart. Expression of genes encoding cardiac muscle proteins, membrane $\mathrm{Ca}^{2+}$ channels, and cell membrane ion transport and intracellular $\mathrm{Ca}^{2+}$ transport proteins were variously altered. Myh6, Tnnt2, Cacna2d3, Slc9a1, and Atp2a2 were downregulated while Myl2, Cacna1g, Cacna1h, and Atp2a1 were upregulated in ZDF ventricle compared to ZL controls. Well-preserved ventricular myocyte shortening was linked to an altered pattern of genes encoding different $\mathrm{Ca}^{2+}$ signaling and cardiac muscle proteins in aged ZDF rats $[42,43]$.

In another study, increased mechanical stiffness, altered extracellular matrix $x_{2}$ and a pro-fibrotic gene expression profile were observed in the aorta of the insulin-insulin-resistant $\mathrm{ZF}$ fa/fa rat. Mechanical studies in ZF fa/fa aortas demonstrated increased vascular stiffness in longitudinal and circumferential directions compared with ZL controls. The results also demonstrated unequal elevations in developed strain favoring the longitudinal direction, which resulted in a loss of anisotropy. Increased expression of fibronectin and collagen IV3 have been reported in the ZF fa/fa aorta. Similarly, mRNA expression of transforming growth factor and numerous Smad proteins were increased in vessels from insulin resistant animals implicating a role for hyperinsulinemia in vascular stiffness. These data provide -mechanical, structural, and molecular evidence for arteriosclerosis in the ZF fa/fa rat, all of which are hallmarks of DCM [44].

Previous studies have shown that T2DM that is linked to CVD progression in female and male ZDF rats is mechanistically and structurally different [45]. Male rats display cardiac fibrosis and significant inhibition of intra-cardiac anti-fibrotic and anti-inflammatory cytokines. On the other hand, female rat hearts are protected from loss of anti-fibrotic cytokines and do not develop fibrosis. However, they still exhibit cardiac and cardiomyocyte hypertrophy, as shown by increased phosphorylation of Ser2448 residue of mTOR. Reduced capillary density was common in both male and female rats. It is possible that cardiac hypertrophy, capillary rarefaction, and a female-specific loss of cardio-reparative angiotensin II receptor 2 (Agtr2) in the setting of a very 
high expression of pro-hypertrophic miR-208a (a biomarker that promotes cardiac hypertrophy) could have contributed to increased myocardial structural damage in the form of cardiomyocyte loss and scarring. This study highlights the need for new cardiac assessments such as noninvasive imaging in diabetic female patients to detect myocardial deformation, cardiac hypertrophy and capillary density [45].

\section{Involvement of micro-RNA in diabetic cardiomyopathy}

Micro-RNAs may provide valuable insight into disease progression. Micro-RNAs are small noncoding RNAs around 22 nucleotides in length that regulate expression of target genes through sequence-specific hybridization to the $3^{\prime}$ untranslated region of messenger RNAs and either block translation or direct degradation of their target messenger RNA [46]. In a study by Delic et al. [47], the onset and progression of DM was followed in ZDF rats from 6 until $17 \underline{17}$ weeks of age. Using TaqMan miRNA arrays, circulating micro-RNAs were measured from plasma samples at four time points: pre-diabetes ( $6 \underline{6} \underline{6}$ weeks), hyperinsulinemia ( $8 \underline{8}$ weeks), $\beta$ cell failure (11- $\underline{11}$ weeks) ${ }_{2}$ and late-stage diabetes ( $17 \underline{17}$ weeks). Analysis of the data revealed variations of circulating micro-RNAs over time. Several micro-RNAs were found to be increased over the course of the disease progression including miR-122, miR-133, miR-210, and miR-375. The most significantly decreased micro-RNAs were miR-140, miR-151-3p, miR-185, miR-203, miR-434-3p and miR-450a. Some of the micro-RNAs have also been identified in T2DM patients. Hence, micro-RNAs potentially provide useful biomarkers for T2DM progression [46].

The effects of aerobic exercise training (AET) on miRNA-16 and its target gene vascular endothelial growth factors (VEGF) have also been investigated in ZF rats. AET induced cardiac angiogenesis and reversed the microvascular rarefaction in the ZF rats. Revascularization is associated with a decrease in miRNA-16 expression and an increased VEGF protein expression, suggesting a mechanism for potential therapeutic application in vascular diseases [48].

\section{Autonomic innervation in the Zucker rat}

Increased very-_low-density lipoprotein-triglyceride (VLDL-TG) secretion by the liver in ZF (fa/fa) rat model for dyslipidemia is due to relative hyperactivity of sympathetic and/or hypoactivity of parasympathetic hepatic innervation [49]. Experiments have been performed to investigate the involvement of the autonomic nervous system by surgical denervation of either 
the sympathetic or parasympathetic hepatic nerves in $\mathrm{ZF}$ rats. The results demonstrate that cutting the sympathetic hepatic nerve lowers VLDL-TG secretion in obese rats subsequently

lowering plasma TG concentrations after $6 \underline{6}$ weeks. On the other hand, a parasympathetic denervation resulted in an increased plasma total cholesterol concentration. The effects of either sympathetic or parasympathetic denervation of the liver were independent of changes in humoral factors or changes in body weight or food intake. In summary, there is much evidence to indicate that sympathetic denervation improves the lipid profile in ZF rats, while parasympathetic denervation increases total cholesterol levels [49].

\section{Mechanisms underlying diabetic cardiomyopathy in the Zucker diabetic fatty rat}

Marked systolic dysfunction in T1DM is linked with severe nitro-oxidative stress, apoptosis, and fibrosis. These pathological features are either less noticeable or absent, while cardiomyocyte hypertrophy was comparable in T2DM, which is linked to unaltered systolic function and increased diastolic stiffness. mRNA-expression of hypertrophy markers c-fos, c-jun, and $\beta$ MHC, in addition to pro-apoptotic caspase-12, is elevated in T1DM, while it persisted or only slightly increased in T2DM. Expression of the profibrotic TGF- $\beta_{1}$ is upregulated in T1DM and showed a decrease in T2DM [50].

In ventricular myocytes from $\mathrm{ZDF}$ rats, alterations in the time course of contraction and $\mathrm{Ca}^{2+}$ transients could be due to changing expression of genes encoding myosin heavy chain and Ltype $\mathrm{Ca}^{2+}$ channel proteins [42]. At the early stages of DM, changing the pattern of genes encoding cardiac muscle regulatory proteins, may provide biomarkers signaling the onset of cardiac muscle pathophysiology and opportunities for corrective interventions in T2DM heart [42].

At 11 weeks of age, experiments in the isolated perfused ZDF heart demonstrated preserved endothelium-dependent dilatation of the coronary microvasculature regardless of the increased oxidative stress, depressed cardiac mechanical function and coronary flow [51]. -Another study investigated whether skeletal muscle arteriolar vasoconstrictor dysfunction comes first or occurs simultaneously with the onset of diabetes and hypertension. Male ZDF rats, aged 7, 13, and 20 $\underline{20}$ months, were used to represent pre-diabetic, short-term and long-term diabetic states, 
respectively [52]. Vasoconstrictor responses, passive mechanical properties of isolated skeletal muscle arterioles as well as conscious mean arterial pressure (MAP), fasting plasma insulin and glucose were measured. The study concluded that the changes in vascular function resulting from $\mathrm{T} 2 \mathrm{DM}$ at the selected time points are distinct in the progression of this disease. Also, in skeletal muscle arteriole, increased vasoconstrictor responses to norepinephrine (NE) and endothelin-1 (ET-1) in pre-diabetes are arbitrated by a decrement in the counter-influence of the NOS (nitric oxide synthase) signaling mechanism. The results of this study [52] suggested that an early increase in adrenergic- and ET-1-mediated vasoconstriction contribute to the synchronized emergence of hypertension and diabetes. Additionally, it also suggested that interventions intended to increase NO (nitric oxide) bioavailability during the pre-diabetic state may help combat the hypertension associated with the onset of T2DM [52].

Development of T2DM in ZDF rats and the impact of ageing on cardiomyocyte function have been -investigated by Fulop et al.- [53]. Their studies demonstrated that an increase in O-linked $\mathrm{N}$-acetylglucosamine (O-GlcNAc) on specific proteins may contribute to impaired cardiomyocyte function in diabetes and the -elevated level of O-GlcNAc on different proteins appears to be differentially regulated by age and diabetes [53].

Recently, an emerging mediator of cardiac contractility was found to be the myocardial isoform of $\mathrm{Ca}^{2+} /$ calmodulin-dependent protein kinase II-delta (CaMKII $\delta$ ). It is a multifunctional serine/threonine protein kinase that regulates proteins associated with cardiac $\mathrm{Ca}^{2+}$ flux, including RYR and L-type $\mathrm{Ca}^{2+}$ channels as well as proteins integral to sarcomere cross bridge cycling and structure. CaMKII $\delta$ plays an important role in cardiac contraction and relaxation. Persistent activation of CaMKII $\delta$ is linked to some cardiac pathologies, including maladaptive hypertrophy, apoptosis and arrhythmias. CaMKII $\delta$ activity was found to be enhanced during hyperglycemia and may alter intracellular $\mathrm{Ca}^{2+}$ handling in cardiomyocytes, ultimately leading to reduced cardiac performance. Daniels et al. [51] investigated the effects of CaMKII $\delta$ on cardiac contractility in ZDF rats. Their results showed that CaMKII $\delta$ has a crucial role in modulating performance of the diabetic heart, suggesting a potential therapeutic role for $\mathrm{Ca}^{2+} /$ calmodulindependent kinase II (CaMKII) inhibitors in improving myocardial function during T2DM [54].

Cardiac NE overflow was also investigated in ZDF rats. The results indicate that cardiac NE overflow is inhibited in failing hearts from ZDF rats which may result from the inhibition of 
functional alterations of presynaptic alpha 2-adrenoceptors and may contribute to cardiac autonomic neuropathy [55].

The relationship between cardiomyocyte rich perivascular tissue and coronary arteries has been investigated in ZDF rats. Specifically, the vasoactive effects of perivascular tissue in arteries from the ZDF rat was compared with other animal models of T2DM. Vasocontractile and vasorelaxant functions of coronary septal arteries with and without perivascular tissue were investigated using wire myography. The experiments confirmed the anti-contractile influences of perivascular tissue are weakened in coronary arteries from ZDF rats, but unaffected in arteries from STZ treated rats. Endothelial dysfunction was reported in coronary septal arteries, with and without perivascular tissue, from ZDF rats but not STZ treated rats. Different signaling between cardiomyocyte rich perivascular tissue and coronary arteries can contribute to cardiovascular complications in T2DM [56].

In isolated hearts from ZDF rats, the impact of altered substrate utilization on cardiac function was investigated to determine whether changes in cardiac metabolism in T2DM are associated with contractile dysfunction or impaired response to ischemia. Hearts from ZDF and ZL control rats were isolated and perfused with glucose, lactate, pyruvate, and palmitate. The experiments showed that a shift from carbohydrates to fatty acids for oxidative energy production did not increase myocardial oxygen consumption and was not linked with impaired response to ischemia and reperfusion [57].

The storage of fat within heart muscle has been linked with decreased force production, which has consequences for the heart to pump blood effectively and lipid accumulation within cardiac muscle has been associated with heart failure. Fats from the blood can be moved into heart muscle cells, where they can either be stored or used for generating energy within the mitochondria. Experiments in the ZDF rat demonstrated that more fat accumulates within the heart as a result of their increased transport across the membranes of heart cells, not due to reductions in mitochondrial number or function, indicating that lipids accumulate in the heart despite normal mitochondrial content, long-chain fatty acid oxidation and morphology [58]. Instead, increased sarcolemma long-chain fatty acid (LCFA) transport proteins and rates of LCFA transport result in a greater number of lipid droplets within cardiac muscle [58]. 


\section{Mechanisms underlying electro-mechanical dysfunction in the Zucker diabetic fatty rat heart}

Early signs of diabetic autonomic neuropathy in the electrocardiogram include elevated R wave amplitudes, widening of QTc intervals and decreased heart rate variability (HRV). The severity of neuropathy has a direct relationship with mortality risk. AET is a common recommendation for the postponement and possible reversal of cardiac dysfunction. Limited research is currently available on the effects of AET on the electrocardiogram in the ZDF rat. One study demonstrated alterations in R wave amplitudes, HRV, QT and QTc intervals in ZDF rats. AET had beneficial effects and was able to correct $\mathrm{R}$ wave amplitude changes as well as electrocardiogram correlates of left ventricular mass [59].

Experiments have been performed in SAN from the right atria of male Sprague-Dawley, ZF and ZL rats, as well as the ventricles of male Sprague-Dawley rats to investigate the direct actions of leptin on heart rate and ventricular repolarization. Leptin is a 16-kda adipokine released from adipocytes acting through its receptor. Leptin receptors and adipocytes are present in the myocardium. It has been proposed that leptin can modulate cardiac electrical properties via $\beta$ adrenergic receptor activation and that it can directly modulate cardiac electrical properties such as heart rate and QT interval via its receptor. The results from the study showed that leptin, at low doses $(0.1-30 \underline{30} \mu \mathrm{g} / \mathrm{kg})$, decreased resting heart rate while at high doses $(150-300-\mu \mathrm{g} / \mathrm{kg})$, ; it induced a biphasic effect (decrease and then increase) on heart rate. In the presence of the $\beta$ blocker propranolol $(30 \underline{30} \mathrm{mg} / \mathrm{kg})$, high-dose leptin only reduced heart rate and occasionally caused ventricular tachycardia and sinus pauses. This leptin-induced inhibition of resting heart rate was fully reversed by leptin antagonist. Leptin also increased the QTc interval, however, leptin antagonist did not reverse these effects. Furthermore, in isolated ventricular myocytes, leptin $(0.03-0.3-\underline{3} \mu \mathrm{g} / \mathrm{ml})$ reversibly increased APD. In summary, leptin can directly decrease heart rate and increase QT interval via its receptor independent of $\beta$-adrenergic receptor stimulation. During inhibition of $\beta$-adrenergic receptor activity, high concentrations of leptin in the myocardium can cause bradycardia, prolonged QT interval, and ventricular arrhythmias. In general, these findings may offer a better understanding of higher incidence of prolonged QT and sudden cardiac death in obesity [60]. 
The sympathetic nervous system exerts its chronotropic, inotropic and lusitropic effects on the heart mainly by means of $\beta$-adrenoceptors ( $\beta$-ARs), of which three different $\beta$-AR subtypes $(\beta 1$, $\beta 2$ and $\beta 3$ ) exist [61]. Impaired $\beta$-adrenoceptor ( $\beta$-AR) responsiveness can have consequences for heart function in patients with T2DM. For this reason, specific $\beta 1$ and $\beta 2-\mathrm{AR}$ responsiveness of heart rate, contraction and relaxation in the diabetic heart were investigated. In general, diabetic hearts showed lower basal heart rates compared to controls. AMP-activated protein kinase (AMPK), a key regulator of cardiac energy metabolism [62], which was also linked to $\beta$ $\mathrm{AR}$, and specifically to $\beta 2-\mathrm{AR}$ had $41 \%$ higher protein phosphorylation levels in diabetic heart [63-65]. In summary, $\beta 1$-adrenoceptors are the main subtype regulating heart rate, contraction, and relaxation which in turn regulate chronotropic, inotropic, and lusitropic $\beta$-AR responses in the healthy heart and the T2DM heart. Moreover, the $\beta 2$-AR subtype indirectly supports the $\beta 1$ AR functional response in the diabetic heart [66].

Mortality and morbidity following an acute myocardial infarction in patients with T2DM may be caused by increased sensitivity to either ischemia reperfusion (IR) injury or altered activation of endogenous cardioprotective pathways modified by T2DM or ischemic preconditioning (IPC). Results from a previous study [67] showed that IPC reduced infarct size in all groups irrespective of the presence of T2DM and its duration. Compared to prediabetic rats, myocardial glucose oxidation rates were reduced during stabilization and early reperfusion at the onset of T2DM, but these animals retained the ability to increase oxidation rate in late reperfusion. Nevertheless, late stage diabetic rats had low glucose oxidation rates throughout reperfusion and stabilization. Regardless of intrinsic differences in sensitivity to IR injury, the cardioprotective effect of IPC was conserved in pre, early, and late stage T2DM and was associated with adaptations to myocardial glucose oxidation capacity [67].

As mentioned earlier in the review, CaMKII $\delta$ plays an important role in cardiac contraction and relaxation. Since it plays an important part in altering intracellular $\mathrm{Ca}^{2+}$ transport in cardiomyocytes, ultimately leading to reduced cardiac performance, it is important to consider it as one of the mechanisms underlying electro-mechanical dysfunction in ZDF hearts [54]. An example of such dysfunction is AF which is associated with high morbidity and mortality. Both structural and electrical remodeling contribute to AF. A role for $\mathrm{Ca}^{2}+/$ calmodulin-dependent protein kinase II (CaMKII) in the regulation of persistent late $\mathrm{Na}^{+}$current has been identified. A 
computational approach was used to test the hypothesis that increased CaMKII-activated late $\mathrm{Na}^{+}$current in atrial myocytes alters $\mathrm{Ca}^{2}+$ homeostasis thereby contributing to arrhythmogenic after-depolarizations. Dynamic CaMKII activity and regulation of multiple downstream targets including late $\mathrm{Na}^{+}$current, L-type $\mathrm{Ca}^{2}+$ current, phospholamban, and the SR RYR Ca ${ }^{2+}$-release channel, were combined into an existing well-validated computational model of the human atrial action potential. Model simulations showed that constitutive CaMKII-dependent phosphorylation of $\mathrm{Na}_{\mathrm{V}} 1.5$ and the subsequent increase in late $\mathrm{Na}^{+}$current upset intracellular atrial myocyte CaMKII signaling and $\mathrm{Ca}^{2+}$ homeostasis. Increased late $\mathrm{Na}^{+}$current promotes intracellular $\mathrm{Ca}^{2+}$ overload via forward mode $\mathrm{Na}^{+} / \mathrm{Ca}^{2}+$ exchange activity, which increases $\mathrm{RYR}$ open probability beyond that observed for CaMKII-dependent phosphorylation of RYR alone. Increased late $\mathrm{Na}^{+}$ current contributes to atrial myocyte repolarization defects (afterdepolarizations and alternans) in the setting of acute $\beta$-adrenergic stimulation. The model was used in an effort to help in identifying new mechanisms for atrial $\mathrm{Na}_{\mathrm{V}} 1.5$ regulation with direct relevance to human AF [68].

In T2DM, impaired endothelium-dependent relaxation is due to a loss of endothelium derived hyperpolarization (EDH) that is controlled by diminished ion channel function in ZDF and ZL rats. It is proposed that the compensatory effect of NO and EDH-associated, endotheliumdependent relaxation is reduced in ZDF rats. Specific blockade of $\mathrm{IK}_{\mathrm{Ca}}$ with TRAM-34 reduces $\mathrm{NO}$ and EDH-type relaxation in diabetic rats, indicating an elevated contribution of $\mathrm{IK}_{\mathrm{Ca}}$ in diabetic small mesenteric artery (SMA) relaxation. This result associates with increased $\mathrm{IK}_{\mathrm{Ca}}$ mRNA and protein expression which suggests an important role for $\mathrm{IK}_{\mathrm{Ca}}$ in diabetic SMA as a target for innovative treatment strategies [69].

Decreased conduction velocity $(\mathrm{CV})$, which is determined by excitability, internal electrical resistance and cardiac structure, is an independent risk factor for re-entry arrhythmias. The internal electrical resistance can be viewed as two resistors in series: first, the resistance of the cell cytoplasm, which is determined by the cellular composition, e.g., the number of intracellular organelles and non-conducting material like lipid droplets and second, the resistance at the cellcell junctions [70]. It was found out that the $\mathrm{CV}$ is reduced in ZDF rats. The CV disturbance may be partially explained by increased lateralization of connexin43. Moreover, lipotoxicity may play a role in development of conduction disturbances and arrhythmias in T2DM [71]. 
By comparing speckle-tracking echocardiography (STE)-derived parameters to the indices of left ventricular pressure volume (LVPV) analysis to detect cardiac dysfunction in rat models of T1DM (STZ) and T2DM (ZDF), it was found that in T1DM, contractility and active relaxation deteriorated to a greater extent compared to T2DM. In contrast, diastolic stiffness was impaired in T2DM. Similarly, STE revealed more severe systolic dysfunction in T1DM. Among diastolic STE parameters, peak strain rate values in isovolumic relaxation (SrIVR) was-were more decreased in T1DM-; however, peak strain rate values in early diastole $(\mathrm{SrE})$ was-were more reduced in T2DM. In T1DM, peak strain rate values in systole $(\mathrm{SrS})$ correlated with contractility, SrIVR with active relaxation, while in T2DM SrE was related to cardiac stiffness, cardiomyocyte diameter, and fibrosis. In summary, strain and strain rate parameters provide valuable physiological measures of dynamic changes in contractility, active relaxation ${ }_{2}$ and LV stiffness in animal models of T1DM and T2DM. STE corresponds to PV analysis and also correlates with markers of histological myocardial remodeling [72]. Figure 5 shows the possible mechanism(s) of electro-mechanical dysfunction in T2DM heart.

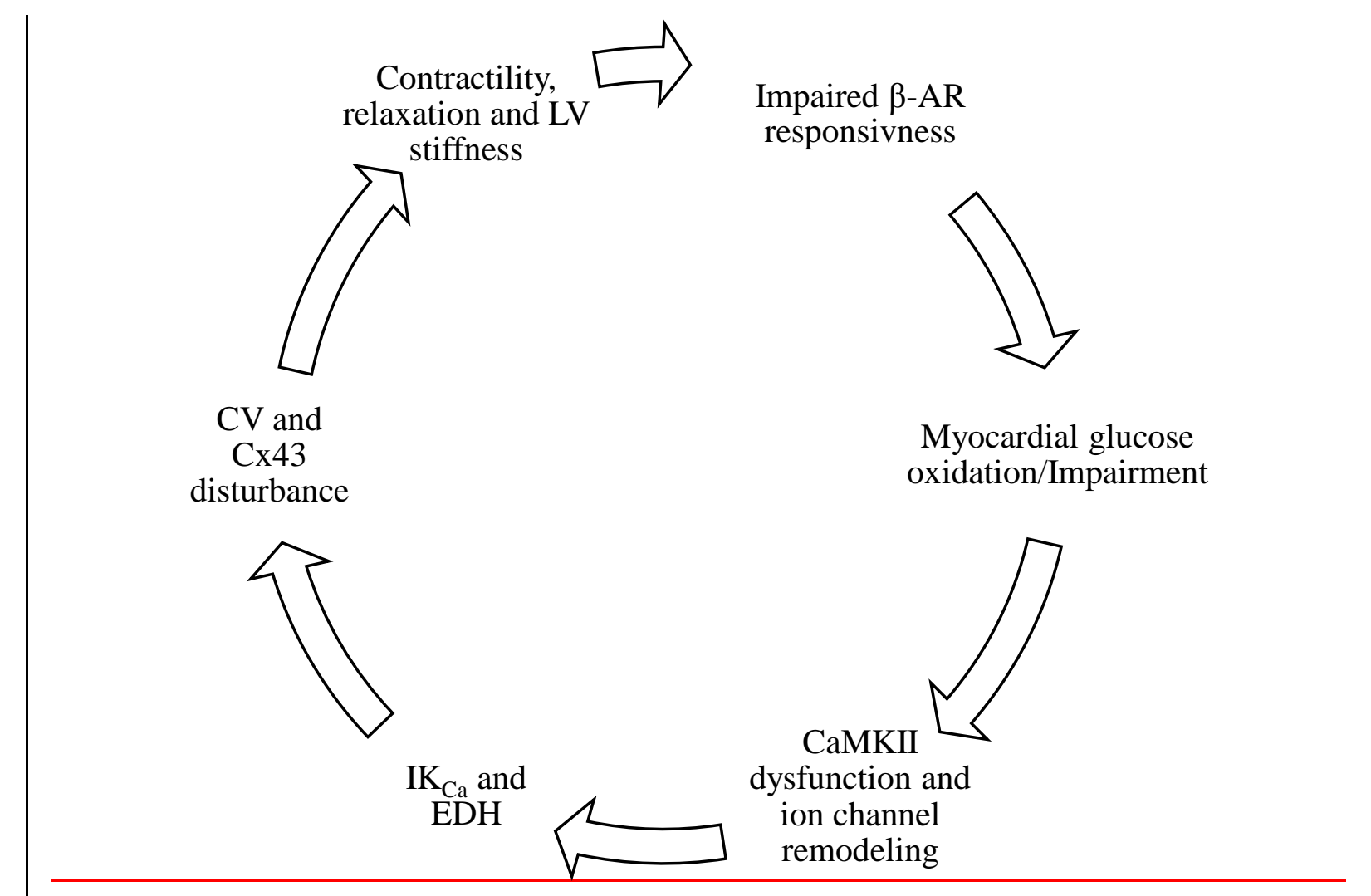

Figure-Fig. 5: Possible mechanism(s) of electro-mechanical dysfunction in T2DM heart 


\section{Conclusion}

Figure 6 summarizes the time course of pathological changes that are taking place in the ZDF rat heart and that may lead to sudden cardiac death. This review provides evidence that the obeseinduced ZDF rat model is a useful experimental model to study the pathophysiology induced by T2DM and obesity in different organs of the body, especially the heart. In terms of mechanical function of ZDF heart, the change in time course of contraction and $\mathrm{Ca}^{2+}$ transients may be due to changing expression of genes encoding L-type $\mathrm{Ca}^{2+}$ channel proteins [42]. The cardiac contractility and the myocardial isoform of $\mathrm{Ca}^{2+} /$ calmodulin-dependent protein kinase II (CaMKII $)$ were found to be important in cardiac performance [54]. However, more studies are required to clarify the cellular, subcellular, and molecular basis of electro-mechanical dysfunction in the ZDF rat heart since they can lead to bradyarrhythmias and sudden cardiac death.

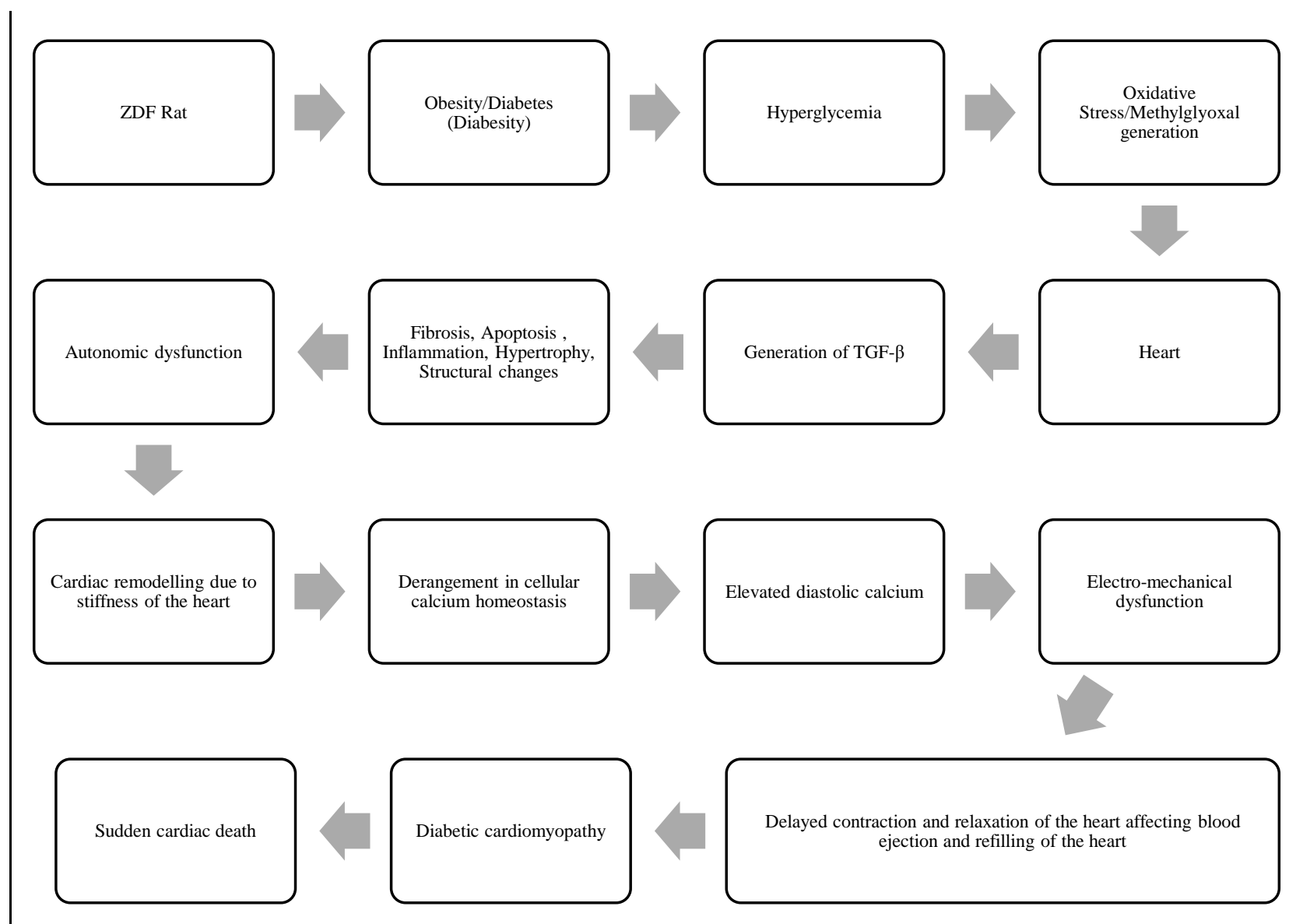


Figure-Fig. 6:- Flow diagram summarizing the pathological changes that are taking place in the ZDF rat heart, subsequently leading to sudden cardiac death\}

\section{References}

1. International Diabetes Federation (2017) IDF Diabetes Atlas, 8th edn. Int. Diabetes Fed, pp 40-95

2. Mayfield J (1998) Diagnosis and Classification of Diabetes Mellitus: New Criteria. Am Fam Physician 58:1355-1362. 10.2337/dc14-S081

3. Low Wang CC, Hess CN, Hiatt WR, Goldfine AB (2016) Clinical update: Cardiovascular disease in diabetes mellitus. Circulation 133:2459-2502.

10.1161/CIRCULATIONAHA.116.022194

4. Altunkeser BB, Ceylan E, Demir K, Yilmaz A, Avci A, Kaya Z, Ersecgin A, Marakoglu K, Armutlukuyu M (2015) Assessment of atrial electromechanical delay and P-wave dispersion in patients with type 2 diabetes mellitus. J Cardiol 67:378-383. 10.1016/j.jjcc.2015.06.003

5. World Health Organization (2018) Fact Sheets. Obesity and overweight. In: WHO. https://www.who.int/en/news-room/fact-sheets/detail/obesity-and-overweight

6. NHLBI Obesity Education Initiative Expert Panel. National Institutes of Health. National Heart Lung and Blood Institute. The Practical Guide: Identification, Evaluation, and Treatment of Overweight and Obesity in Adults. NIH Publ No. 00-4084

7. Swinburn BA, Kraak VI, Allender S, et al (2019) The Global Syndemic of Obesity, Undernutrition, and Climate Change: The Lancet Commission report. Lancet 393:791-846. 10.1016/S0140-6736(18)32822-8

8. Gurevich-Panigrahi T, Panigrahi S, Wiechec E, Los M (2009) Obesity: pathophysiology and clinical management. Curr Med Chem 16:506-521

9. Dobbs R, Swinburn B (2015) The global obesity threat. In: Projuct Synd. McKinsey Glob. 
Inst. https://www.mckinsey.com/mgi/overview/in-the-news/the-global-obesitythreat. Accessed 6 Jun 2019

10. Vasanji Z, Dhalla NS, Netticadan T (2004) Increased inhibition of SERCA2 by phospholamban in the type I diabetic heart. Mol Cell Biochem 261:245-249

11. Howarth FC, Parekh K, Jayaprakash P, Inbaraj ES, Oz M, Dobrzynski H, Adrian TE (2017) Altered profile of mRNA expression in atrioventricular node of streptozotocininduced diabetic rats. Mol Med Rep 16:3720-3730. 10.3892/mmr.2017.7038

12. Weyer C, Funahashi T, Tanaka S, Hotta K, Matsuzawa Y, Pratley RE, Tataranni PA (2001) Hypoadiponectinemia in Obesity and Type 2 Diabetes: Close Association with Insulin Resistance and Hyperinsulinemia. J Clin Endocrinol Metab 86:19301935. 10.1210/jcem.86.5.7463

13. Yokoi N, Hoshino M, Hidaka S, Yoshida E, Beppu M, Hoshikawa R, Sudo K, Kawada A, Takagi S, Seino S (2013) A Novel Rat Model of Type 2 Diabetes: The Zucker Fatty Diabetes Mellitus ZFDM Rat. J Diabetes Res 2013:103731-103740. $10.1155 / 2013 / 103731$

14. Harvey RA, Ferrier D (2011) Lippincott's Illustrated Reviews: Biochemistry. In: Harvey RA, Ferrier D (eds) 5th ed. Wolters Kluwer Health, Lippincott Williams \& Wilkins, Philadelphia pp 307-356

15. Klabunde RE (2017) Cardiac electrophysiology: normal and ischemic ionic currents and the ECG. Adv Physiol Educ 41:29-37. 10.1152/advan.00105.2016

16. Crawford M, DiMarco J, Paulus W (2009) Cardiology. https://www.elsevier.com/books/cardiology/crawford/978-0-7234-3485-6. Accessed 10 Oct 2018

17. Boyett MR (2009) "And the beat goes on" the cardiac conduction system: The wiring system of the heart. Exp Physiol 94:1035-1049. 10.1113/expphysiol.2009.046920

18. Kashou AH, Kashou HE (2018) Physiology, Sinoatrial Node (SA Node). In: StatPearls. http://www.ncbi.nlm.nih.gov/pubmed/29083608. Accessed 10 Nov 2018 
19. Bartos DC, Grandi E, Ripplinger CM (2015) Ion channels in the heart. Compr Physiol 5:1423-1464. 10.1002/cphy.c140069

20. Pinnell J, Turner S, Howell S (2007) Cardiac muscle physiology. Contin Educ Anaesth Crit Care Pain 7:85-88. 10.1093/bjaceaccp/mkm013

21. Hafeez Y, Grossman SA (2018) Rhythm, Junctional. In: StatPearls [internet]. http://www.ncbi.nlm.nih.gov/pubmed/29939537. Accessed 10 Nov 2018

22. Czick ME, Shapter CL, Silverman DI (2016) Atrial Fibrillation: The Science behind Its Defiance. Aging Dis 7:635-656. 10.14336/AD.2016.0211

23. Silverthorn DU, Ober WC, Garrison CW, Silverthorn AC, Johnson BR (2007) Human physiology : an integrated approach. In: Regulation, 4th ed. Pearson Education Inc/Benjamin Cummings, San Francisco, pp 379-386

24. Pfeiffer ER, Tangney JR, Omens JH, McCulloch AD (2014) Biomechanics of cardiac electromechanical coupling and mechanoelectric feedback. J Biomech Eng 136:021007-021018. 10.1115/1.4026221

25. Bers DM, Despa S (2013) Cardiac Excitation-Contraction Coupling. Encycl Biol Chem Second Ed 415:379-383. 10.1016/B978-0-12-378630-2.00221-8

26. Landstrom AP, Dobrev D, Wehrens XHT (2017) Calcium Signaling and Cardiac Arrhythmias. Circ Res 120:1969-1993

27. Shih H-TT (1994) Anatomy of the Action Potential in the Heart. Tex Heart Inst J 21:30-41

28. Towbin JA (2004) Molecular genetic basis of sudden cardiac death. Pediatr Clin N Am 51:1229-1255. 10.1016/j.pcl.2004.04.012

29. Snyders DJ (1999) Structure and function of cardiac potassium channels. Cardiovasc Res 42:377-390. 10.1016/S0008-6363(99)00071-1

30. Hille B (1978) Ionic channels in excitable membranes. Current problems and biophysical approaches. Biophys J 22:283-294. 10.1016/S0006-3495(78)85489-7

31. Huang H, Pugsley MK, Fermini B, Curtis MJ, Koerner J, Accardi M, Authier S (2017) 
Cardiac voltage-gated ion channels in safety pharmacology: Review of the landscape leading to the CiPA initiative. J Pharmacol Toxicol Methods 87:11-23. 10.1016/j.vascn.2017.04.002

32. Schaffer SW (1991) Cardiomyopathy associated with noninsulin-dependent diabetes. Mol Cell Biochem 107:1-20. 10.1007/BF02424571

33. Mortuza R, Chakrabarti S (2014) Glucose-induced cell signaling in the pathogenesis of diabetic cardiomyopathy Heart Fail Rev 19:75-86. 10.1007/s10741-013-9381-z

34. Falcão-Pires I, Leite-Moreira AF (2012) Diabetic cardiomyopathy: Understanding the molecular and cellular basis to progress in diagnosis and treatment. Heart Fail Rev 17:325-344. 10.1007/s10741-011-9257-z

35. Isfort M, Stevens SCW, Schaffer S, Jong JC, Wold LE (2014) Metabolic dysfunction in diabetic cardiomyopathy. Heart Fail Rev 19:35-48. 10.1007/s10741-013-9377-8

36. Murarka S, Movahed MR (2010) Diabetic Cardiomyopathy. J Card Fail 16:971-979.

\subsection{6/J.CARDFAIL.2010.07.249}

37. Matafome P, Rodrigues T, Sena C, Seiça R (2017) Methylglyoxal in Metabolic Disorders: Facts, Myths, and Promises. Med Res Rev 37:368-403. 10.1002/med.21410

38. Takaya K, Ogawa Y, Isse N, Okazaki T, Satoh N, Masuzaki H, Mori K, Tamura N, Hosoda K, Nakao K (1996) Molecular cloning of rat leptin receptor isoform complementary DNAs-identification of a missense mutation in Zucker fatty (fa/fa) rats. Biochem Biophys Res Commun 225:75-83. 10.1006/bbrc.1996.1133

39. Bray GA (1977) The Zucker-fatty rat: a review. Fed Proc 36:148-153

40. Baynes JW, Murray DB (2009) The Metal Chelators, Trientine and Citrate, Inhibit the Development of Cardiac Pathology in the Zucker Diabetic Rat. Exp Diabetes Res 2009:696378-696384. 10.1155/2009/696378

41. Raza H, John A, Howarth FC (2012) Alterations in Glutathione Redox Metabolism, Oxidative Stress, and Mitochondrial Function in the Left Ventricle of Elderly Zucker Diabetic Fatty Rat Heart. Int J Mol Sci 13:16241-16254. 
$10.3390 /$ ijms 131216241

42. Howarth FC, Qureshi MA, Hassan Z, Al Kury LT, Isaev D, Parekh K, Yammahi SRKDKD, Oz M, Adrian TE, Adeghate E (2011) Changing pattern of gene expression is associated with ventricular myocyte dysfunction and altered mechanisms of $\mathrm{Ca} 2+$ signalling in young type 2 Zucker diabetic fatty rat heart. Exp Physiol 96:325-337. 10.1113/expphysiol.2010.055574

43. Howarth FC (2012) Ventricular myocyte contraction, intracellular calcium and expression of genes encoding cardiac muscle proteins in young and aging Zucker diabetic fatty rat heart reviewed. Hamdan Med J 5:165-172. 10.7707/hmj.v5i2.140

44. Sista AK, O’Connell MK, Hinohara T, Oommen SS, Fenster BE, Glassford AJ, Schwartz EA, Taylor CA, Reaven GM, Tsao PS (2005) Increased aortic stiffness in the insulin-resistant Zucker fa/fa rat. Am J Physiol Heart Circ Physiol 289:H845H851. 10.1152/ajpheart.00134.2005

45. Lum-Naihe K, Toedebusch R, Mahmood A, Bajwa J, Carmack T, Kumar SA, Ardhanari S, Demarco VG, Emter CA, Pulakat L (2017) Cardiovascular disease progression in female Zucker Diabetic Fatty rats occurs via unique mechanisms compared to males. Sci Rep 7:17823-17839. 10.1038/s41598-017-18003-8

46. Kim GH (2013) MicroRNA regulation of cardiac conduction and arrhythmias. Transl Res 161:381-392. 10.1016/j.trsl.2012.12.004

47. Delic D, Eisele C, Schmid R, Luippold G, Mayoux E, Grempler R (2016) Characterization of micro-RNA changes during the progression of type 2 diabetes in Zucker diabetic fatty rats. Int J Mol Sci 17:665-681. 10.3390/ijms17050665

48. Fernandes T, Casaes L, Soci Ú, Silveira A, Gomes J, Barretti D, Roque F, Oliveira E (2018) Exercise Training Restores the Cardiac Microrna-16 Levels Preventing Microvascular Rarefaction in Obese Zucker Rats. Obes Facts 11:15-24. $10.1159 / 000454835$

49. Bruinstroop E, Eliveld J, Foppen E, Busker S, Ackermans MT, Fliers E, Kalsbeek A (2015) Hepatic denervation and dyslipidemia in obese Zucker (fa/fa) rats. Int J Obes 
50. Radovits T, Korkmaz S, Mátyás C, Oláh A, Németh BT, Páli S, Hirschberg K, Zubarevich A, Gwanmesia PN, Li S, Loganathan S, Barnucz E, Merkely B, Szabó G (2015) An Altered Pattern of Myocardial Histopathological and Molecular Changes Underlies the Different Characteristics of Type-1 and Type-2 Diabetic Cardiac Dysfunction. J Diabetes Res 2015:728741-728753. 10.1155/2015/728741

51. Mourmoura E, Vial G, Laillet B, Rigaudière J-P, Hininger-Favier I, Dubouchaud H, Morio B, Demaison L (2013) Preserved endothelium-dependent dilatation of the coronary microvasculature at the early phase of diabetes mellitus despite the increased oxidative stress and depressed cardiac mechanical function ex vivo. Cardiovasc Diabetol 12:49-66. 10.1186/1475-2840-12-49

52. Laughlin MH, Woodman CR, Ray CA, Behnke BJ, Lesniewski LA, Donato AJ, Delp MD (2008) Decreased NO signaling leads to enhanced vasoconstrictor responsiveness in skeletal muscle arterioles of the ZDF rat prior to overt diabetes and hypertension. Am J Physiol Circ Physiol 294:H1840-H1850.

\subsection{2/ajpheart.00692.2007}

53. Fulop N, Mason MM, Dutta K, Wang P, Davidoff AJ, Marchase RB, Chatham JC (2006) Impact of Type 2 diabetes and aging on cardiomyocyte function and O-linked $\mathrm{N}$ acetylglucosamine levels in the heart. AJP Cell Physiol 292:C1370-C1378. 10.1152/ajpcell.00422.2006

54. Daniels LJ, Wallace RS, Nicholson OM, Wilson GA, McDonald FJ, Jones PP, Baldi JC, Lamberts RR, Erickson JR (2018) Inhibition of calcium/calmodulin-dependent kinase II restores contraction and relaxation in isolated cardiac muscle from type 2 diabetic rats. Cardiovasc Diabetol 17:89-104. 10.1186/s12933-018-0732-x

55. Burgdorf C, Richardt G, Schütte F, Dendorfer A, Kurz T (2006) Impairment of presynaptic $\alpha 2$-adrenoceptor-regulated norepinephrine overflow in failing hearts from Zucker diabetic fatty rats. J Cardiovasc Pharmacol 47:256-262.

10.1097/01.fjc.0000202560.61667.3e 
56. Bonde L, Shokouh P, Jeppesen PB, Boedtkjer E (2017) Crosstalk between cardiomyocyterich perivascular tissue and coronary arteries is reduced in the Zucker Diabetic Fatty rat model of type 2 diabetes mellitus. Acta Physiol 219:227-238. 10.1111/apha. 12685

57. Wang P, Zeng H, Lloyd SG, Bonen A, Chatham JC (2004) Impact of altered substrate utilization on cardiac function in isolated hearts from Zucker diabetic fatty rats. Am J Physiol Circ Physiol 288:H2102-H2110. 10.1152/ajpheart.00935.2004

58. Holloway GP, Snook LA, Harris RJ, Glatz JFCC, Luiken JJFPFP, Bonen A (2011) In obese Zucker rats, lipids accumulate in the heart despite normal mitochondrial content, morphology and long-chain fatty acid oxidation. J Physiol 589:169-180. 10.1113/jphysiol.2010.198663

59. VanHoose L, Sawers Y, Loganathan R, Vacek JL, Stehno-Bittel L, Novikova L, Al-Jarrah M, Smirnova I V. (2010) Electrocardiographic changes with the onset of diabetes and the impact of aerobic exercise training in the Zucker Diabetic Fatty (ZDF) rat. Cardiovasc Diabetol 9:56-66. 10.1186/1475-2840-9-56

60. Lin Y-CC, Hull R, Huang J, Martin KH, Davis M, Hileman S, Yu H-GG, Martin KH, Hull R, Davis M, Yu H-GG (2015) Leptin decreases heart rate associated with increased ventricular repolarization via its receptor. Am J Physiol Circ Physiol 309:H1731-H1739. 10.1152/ajpheart.00623.2015

61. Wilson C, Lincoln C (1984) Beta-adrenoceptor subtypes in human, rat, guinea pig, and rabbit atria. J Cardiovasc Pharmacol 6:1216-1221

62. Hardie DG, Hawley SA, Scott JW (2006) AMP-activated protein kinase - development of the energy sensor concept. J Physiol 574:7-15. 10.1113/jphysiol.2006.108944

63. Li J, Yan B, Huo Z, Liu Y, Xu J, Sun Y, Liu Y, Liang D, Peng L, Zhang Y, Zhou Z-N, Shi J, Cui J, Chen Y-H (2010) $\beta 2$ - but not $\beta 1$-adrenoceptor activation modulates intracellular oxygen availability. J Physiol 588:2987-2998.

10.1113/jphysiol.2010.190900

64. Pérez-Schindler J, Philp A, Baar K, Hernández-Cascales J (2011) Regulation of contractility 
and metabolic signaling by the $\beta 2$-adrenergic receptor in rat ventricular muscle. Life Sci 88:892-897. 10.1016/j.lfs.2011.03.020

65. Bussey CT, Thaung HPA, Hughes G, Bahn A, Lamberts RR (2018) Cardiac $\beta$-adrenergic responsiveness of obese Zucker rats: The role of AMPK. Exp Physiol 103:10671075. 10.1113/EP087054

66. Cook RF, Bussey CT, Fomison-Nurse IC, Hughes G, Bahn A, Cragg PA, Lamberts RR (2019) $\beta 2$-Adrenoceptors indirectly support impaired $\beta 1$-adrenoceptor responsiveness in the isolated type 2 diabetic rat heart. Exp Physiol 104:808-818. 10.1113/EP087437

67. Jensen RV, Jespersen NR, Støttrup NB, Povlsen JA, Hjortbak MV, Bøtker HE, Laursen MR, Hjort J, Løfgren B (2018) Influence of diabetes mellitus duration on the efficacy of ischemic preconditioning in a Zucker diabetic fatty rat model. PLoS One 13:e0192981-e0192997. 10.1371/journal.pone.0192981

68. Onal B, Gratz D, Hund TJ (2017) Ca2+/calmodulin-dependent kinase II-dependent regulation of atrial myocyte late $\mathrm{Na}+$ current, $\mathrm{Ca} 2+$ cycling, and excitability: a mathematical modeling study. Am J Physiol Heart Circ Physiol 313:H1227H1239. 10.1152/ajpheart.00185.2017

69. Schach C, Resch M, Schmid PM, Riegger GA, Endemann DH (2014) Type 2 diabetes: increased expression and contribution of IK Ca channels to vasodilation in small mesenteric arteries of ZDF rats. Am J Physiol Circ Physiol 307:H1093-H1102. 10.1152/ajpheart.00240.2013

70. Kléber AG, Rudy Y (2004) Basic mechanisms of cardiac impulse propagation and associated arrhythmias. Physiol Rev 84:431-488. 10.1152/physrev.00025.2003

71. Ploug T, Braunstein TH, Olsen KB, Holstein-Rathlou N-H, Axelsen LN, Sørensen CM, Nielsen MS, Andersen CB (2013) Myocardial impulse propagation is impaired in right ventricular tissue of Zucker Diabetic Fatty (ZDF) rats. Cardiovasc Diabetol 12:19-30. 10.1186/1475-2840-12-19

72. Benke K, Braun S, Mátyás C, Barta BA, Merkely B, Ruppert M, Lakatos BK, Kovács A, 
Németh BT, Oláh A, Radovits T, Tokodi M (2018) Comparison of speckletracking echocardiography with invasive hemodynamics for the detection of characteristic cardiac dysfunction in type-1 and type-2 diabetic rat models. Cardiovasc Diabetol 17:13-26. 10.1186/s12933-017-0645-0 